\title{
Design and calibration of a test rig for shimmy damper characterization
}

\author{
Mir Sakib Mustashin ${ }^{1 *}$, Kamran Behdinan ${ }^{1}$ \\ ${ }^{1}$ Department of Mechanical and Industrial Engineering, University of Toronto, Toronto, Canada \\ *mir.mustashin@mail.utoronto.ca
}

\begin{abstract}
Shimmy dampers are used to attenuate the oscillatory motion encountered during ground operation of aircraft landing gear. This paper presents the development of a test rig for characterizing nose landing gear shimmy damper. This apparatus was designed to simulate ground operation of an aircraft nose landing gear. A roller drum is used to simulate landing and takeoff speeds, while an impact moment mechanism was used to induce shimmy, forcing shimmy vibration through tire slip. Weights can be used to induce vertical force which simulates the fuselage weight. Initial experimental results are presented to illustrate the operation and performance of the rig.
\end{abstract}

Keywords-shimmy; damper; design; static stress;modal analysis

\section{INTRODUCTION}

The aircraft landing gear may encounter friction induced vibrations during ground operation. Shimmy oscillation is one of the instabilities which is a combined torsional and lateral oscillatory motion having frequency in the range of $10 \mathrm{~Hz}$ to $30 \mathrm{~Hz}$ [1]. Shimmy is caused by the energy transfer from the drag force between the tire and the ground to the landing gear [2]. This is more common in nose landing gear. Growing amplitude of shimmy vibration can bring severe damage to the landing gear and can even result in landing gear collapse. Therefore, most landing gears are equipped with shimmy dampers, which are usually a hydraulic cylinder-piston mechanism that connects between the top and bottom strut to dampen the rotational motion. To evaluate the performance of implementing the damper into the system, it is necessary to test the damper either in runway tests or in the laboratory simulations. Dynamic models produced in literatures need validation by real-world testing. For this purpose, this paper discusses the development and calibration of a test rig that can test the performance of different shimmy dampers.

Though shimmy damper performance analysis through computer simulation can be found in recent literatures, experimental shimmy analysis is very rare in open literatures. Rahmani et al. [3] performed stability analysis of a landing gear model which includes a two-piece strut instead of single strut proposed by Arreaza et al. [4]. The transient simulation of the two strut model was done in [5]. Black [6] mentions landing gear test facility where a flywheel simulates the runway and a mount system simulates the aircraft fuselage. Important factors that affect the tests were outlined such as identifying the differences of laboratory and actual airplane tests like natural frequency of the mount, connections and clearances, friction between tire and flywheel surface etc. Mechanisms to control Shimmy excitation were also mentioned. Kiyoshi et al. [7] studied shimmy vibration of wheeled caster where similar kind test setup was used with a running roller and a pendulum force generator. Constant force impact was generated to the caster by releasing the pendulum from the same position every time. Instead of a rotating drum. Takács [8] used a conveyor belt to simulate forward motion to study elastic model of pneumatic tire.

\section{THE TEST RIG}

\section{A. Design Requirements}

The function of the test rig is to characterize the performance of shimmy dampers in mitigating torsional vibration. It should accommodate mechanisms to verify computationally simulated shimmy damper design. The design is constrained by the lab space size, the entrance door, and available power. The lab acquired a nose landing gear of Piper-31T Cheyenne aircraft (see Figure 1. ) as it is properly sized for the scaled down test rig.

The load on the nose landing gear was estimated by calculating the distribution of the maximum takeoff weight on the NLG (see Figure 1. ). Maximum Take-off weight is 42153.57 $\mathrm{N}$. Total force on the nose landing gear $(\mathrm{N})$ was found to be $7433 \mathrm{~N}$. This is the extreme value. For simulation $7000 \mathrm{~N}$ of force was chosen. A 20 inches diameter roller drum was chosen as a rotating mechanism for simulating ground movement. To drive the drum an electric motor was used which was sized based on maximum take-off speed. To determine the required torque needed, moment of inertia of the drum was gathered from Solidworks geometry, which is $1.4 \mathrm{~kg} . \mathrm{m}^{2}$.

Maximum Take-off velocity is $52 \mathrm{~m} / \mathrm{s}$. The drum's rotational speed was calculated from this to be 2000 . From Solidworks, we optimized the moment of inertia which was used to calculate the torque needed. The required was found out to be 14.3 N.m. To control the speed of the motor an AC drive was selected which controls the motor speed by varying the voltage and frequency of the supply voltage to the motor. For safe operation, we selected 5HP 240V 3-phase variable frequency drive for this 
project. Motor driving current is $9.2 \mathrm{~A}$. The higher current output of the VFD (16.5A) overcomes the initial torque.

(a)

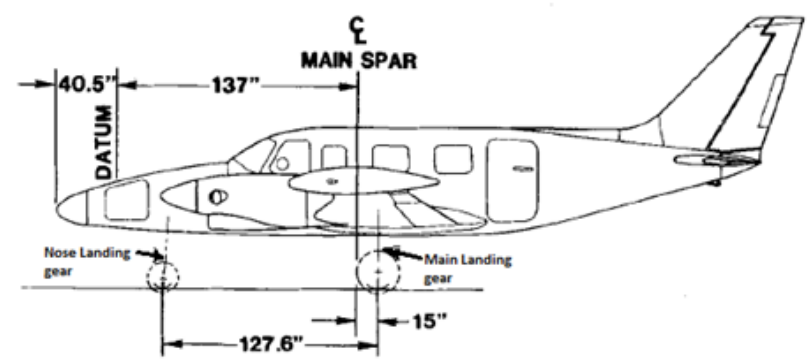

(b)

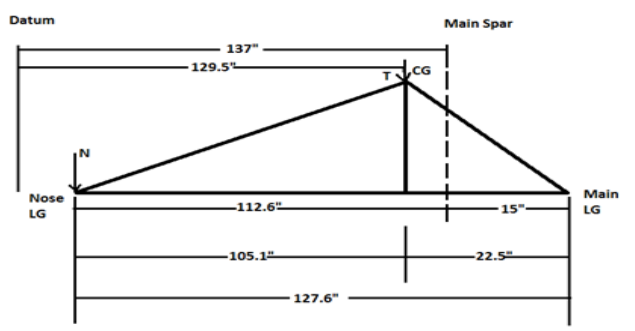

Figure 1. (a) Geometry of PA-31 aircraft from and (b) load distribution diagram

\section{B. Description}

An isometric view of the rig is shown in Figure 2. . There are three parts of the rig structure:

The roller drum shaft is connected to the electric motor via a flexible shaft coupling which allows for minor misalignments. Pillow block bearing on each side of the drum supports the weight of the drum, NLG and mount. The bearings also allow rotation of $2000 \mathrm{rpm}$ of the shaft. Roller drum surface finish was done with glass-tapes to reduce friction between steel surface and the tire.

For the structural frame square tubing made of low carbon steel was used for ease of machinability. The landing gear mount frame is attached to linear bearing sliders which can slide through minimum friction smooth rail shafts that are supported by the inside surface of the side columns. Same square tubes were also used for the base for ease of movement of the structure using forklifts. To dampen the vibration from the structure to ground anti-vibration leveling mount were bolted to the ground which prevents slip during operation. The drag brace joint was modeled with two sliding lock attached by rotating hinge to one of the columns.

This houses the attachment to mount the landing gear using bolt joints. The weights can be put on the holding rod and the whole mount can slide through the linear bearing mentions in the previous section. A long bolt holds the mount with the top beam which can be controlled to fix the mount to certain height in vertical direction.

\section{Finite Element Analysis}

The mesh was generated using HyperMesh commercial software. 2D mesh was created on the midsurface that was extracted from the structural frame. Tetrameshing was used for the support rail. For modeling the joints and weldments one dimensional rigid body elements were used which connects two or more nodes together. To mimic the sliding motion between linear bearing and rail shaft a CBUSH element with zero stiffness in vertical direction and rigid in all other degrees of freedom was selected.

A simple landing gear model was created using the $3 \mathrm{D}$ scan model. Tetrahedral elements with rigid connections was used to model the strut and piston-fork. The tire was connected to the fork with rigid connections and same was done for tire-form contact. All elements were collected in respective components which were assigned properties. The landing gear model the motor was assigned solid elements property and the rest of the structural frame shell element property. Low carbon steel properties outlined in TABLE I. was the chosen material for the structural frame for better machinability. With safety factor of 1.5 , the calculated maximum allowable stress is $211 \mathrm{MPa}$.
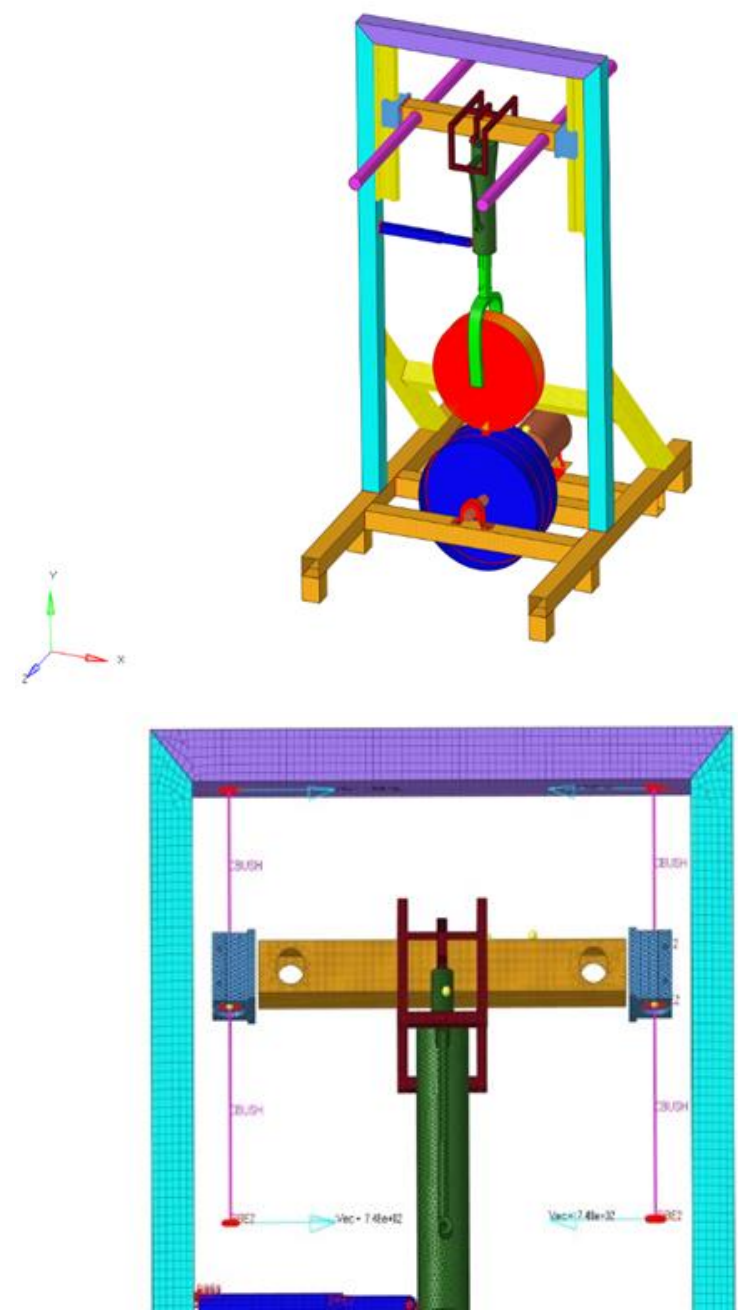

Figure 2. Finite Element model of the rig (top); CBUSH element (bottom) 
TABLE I. ASTM A500 CARBON STEEL PROPETIES

\begin{tabular}{|l|c|c|}
\hline \multicolumn{1}{|c|}{ Description } & Value & Unit \\
\hline Yield Strength & 310 & $\mathrm{MPa}$ \\
\hline Density, $\rho$ & $7.75 \times 10^{-9}$ & $\mathrm{Ton} / \mathrm{mm}^{3}$ \\
\hline Modulus of Elasticity, E & 210 & $\mathrm{GPa}$ \\
\hline Poisson Ratio, $v$ & 0.3 & \\
\hline
\end{tabular}

The first boundary condition is that the feet are constrained in all degrees of freedom. The second boundary condition is the loading case where a load of $7000 \mathrm{~N}$ was distributed among the nodes where weights are to be applied. A final selection of tube lengths and thicknesses were done based on optimum sizes for the tubes during simulation and standard available sizes in the market to reduce machining time.

Linear static stress analysis and modal analysis were performed. Total $7000 \mathrm{~N}$ of force was distributed along the holding rod at nodes where weights to be applied. From the stress analysis results in Figure 3. it was observed the stresses at the bolt join to exceed the limit of $211 \mathrm{MPa}$ which can be solved by using cbush elements for each joint. The limit for the main structure was $165 \mathrm{MPa}$. From the mode shapes only 4 frequencies $(12 \mathrm{~Hz}, 13 \mathrm{~Hz}, 17 \mathrm{~Hz}$ and $29 \mathrm{~Hz})$ reside in the shimmy frequency range. These mode shapes involved the bending mode of weight rod and none of these mode shapes interfered with the landing gear structure. This design was finalized for fabrication.

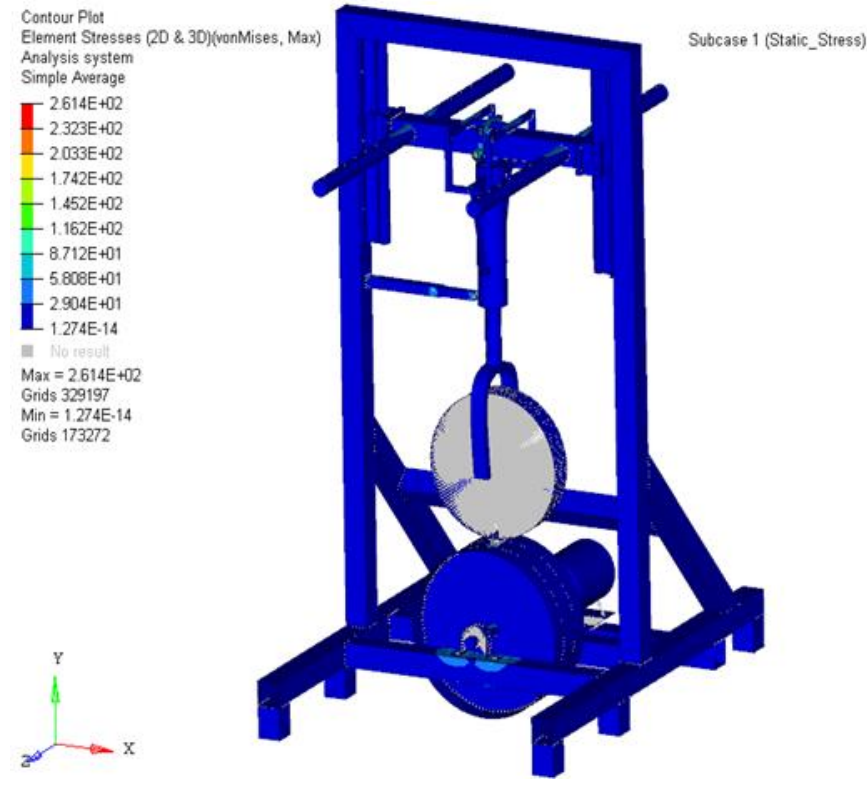

Figure 3. Static stress analysis contour plot

\section{EXPERIMENTAL PROCEDURE}

\section{A. Calibration}

VFD was calibrated for optimum acceleration time, ramp start/stop for safe operation to supply enough current to overcome the initial torque needed to rotate the drum. A sensor mount for placing the linear accelerometer was attached on top of the steering (see Figure 4. Torsional impulse to generate shimmy was generated using an impact hammer as seen in Figure 5. This is a pendulum mechanism where the hammer can be rested on a quick release pin which once release frees the hammer for consistent impact force during operation. Signal from the accelerometers and the force sensor were collected via a Data acquisition system for conditioning and were analyzed in Simcenter Testlab for spectrum and time frequency analysis. Finally, signals were filtered using MATLAB.

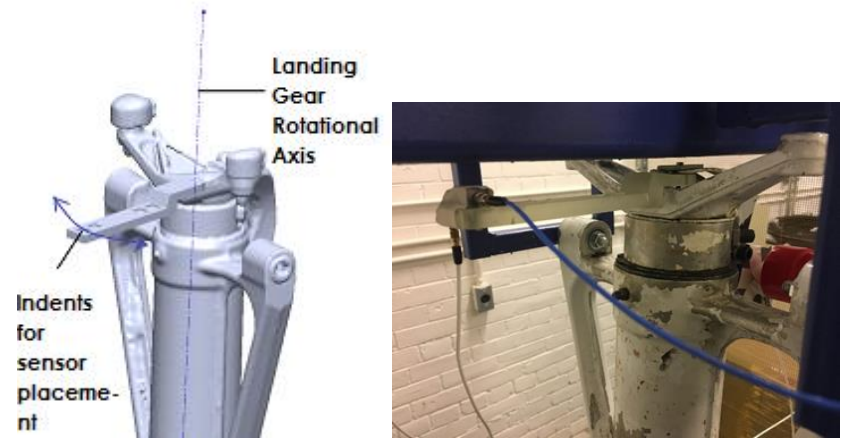

Figure 4. Sensor Mount Attachment

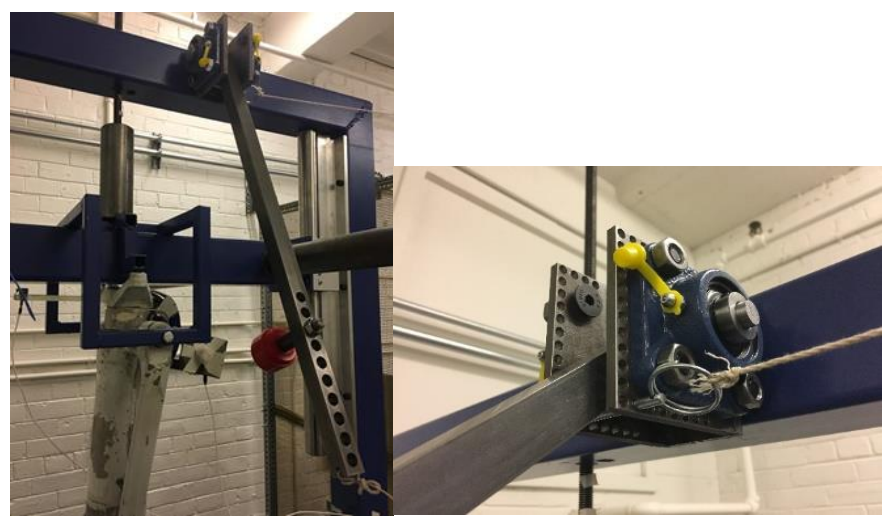

Figure 5. Impact Hammer Assembly (left) and Hammer rested on quick release pin place in one of the holes (right)

\section{B. Shimmy Testing}

The VFD were set to have certain drive frequencies for the motor to rotate at certain rpm's that correspond to desired forward speed. The gear mount is fixed so that no vertical load acts on top of the gear. Once a frequency for the drive is set it is turned on the motor rotates the drum to desired rpm. At this point the hammer pin is released from certain angle corresponding to specific impact force for the hammer to make an impulse to the landing gear. A Sample frequency of $5120 \mathrm{~Hz}$ was chosen for the experiments. Apart from the linear accelerometer placed on the steering mount a rotational accelerometer was used at the bottom of the fork for verification. From the results at Figure 6. , we see the amplitudes from both the sensor reading are same. The time delay is because of the distance between impact force at the steering and sensor placement at the gear fork. Difference between two amplitudes were found to be less than $8 \%$ and between two frequencies were less than $1 \%$. 2nd order Butterworth filter was used with cutoff frequencies in the range of 1-50 Hz. Higher range was chosen to capture more signals that might not be estimated during simulation. 


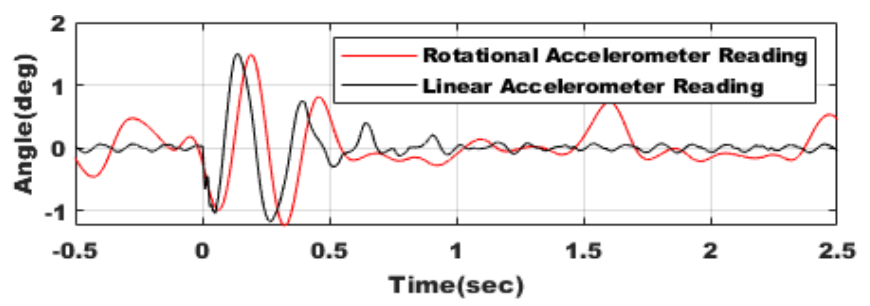

Figure 6. Comparison of responses from two accelerometer placements

\section{RESULTS AND DISCUSSION}

Two test cases are outlined in TABLE II. with 4 different speeds and 2 impacts. Two damping condition one without shimmy damper and one with original shimmy damper as shown in Figure 7. will be tested.

TABLE II. TEST CASES FOR COMPARING RESPONSES

\begin{tabular}{|c|c|c|c|c|c|c|c|c|}
\hline & \multicolumn{3}{|c|}{ Test Case \#1 } & \multicolumn{5}{c|}{ Test Case \#2 } \\
\hline $\begin{array}{c}\text { Forward } \\
\text { Velocity[m/s] }\end{array}$ & 5 & 10 & 15 & 20 & 5 & 10 & 15 & 20 \\
\hline $\begin{array}{c}\text { Impact } \\
\text { Force[N] }\end{array}$ & \multicolumn{3}{|c|}{400} \\
\hline $\begin{array}{c}\text { Vertical } \\
\text { force[N] }\end{array}$ & \multicolumn{3}{|c|}{0} \\
\hline $\begin{array}{c}\text { Torque Link } \\
\text { Angle [ }{ }^{0} \text { ] }\end{array}$ & \multicolumn{3}{|c|}{008} \\
\hline
\end{tabular}

(a)

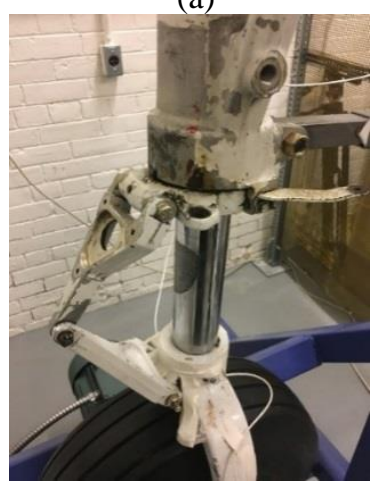

Figure 7. Test condition without (a) and with (b) original shimmy damper

The first peak which is a half sinusoid in the response data can be considered a shock input. Any peaks after this will be considered as shimmy responses. Most of the system noises were observed to be coming from freeplay within the landing gear joints, particularly between steering and upper strut. It can be seen that for the first three speeds even without any shimmy damper, the shimmy vibration gets attenuated due to the landing gear's structural friction damping. At $20 \mathrm{~m} / \mathrm{s}$ both impacts give rise to a phenomenon called limit cycle oscillation where the vibration amplitude grows bigger over time to a maximum and then remains constant.

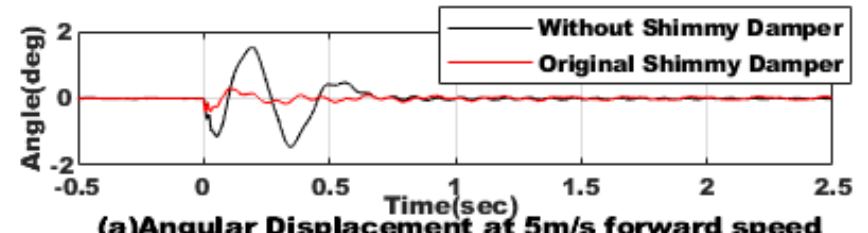

(a)Angular Displacement at $5 \mathrm{~m} / \mathrm{s}$ forward speed
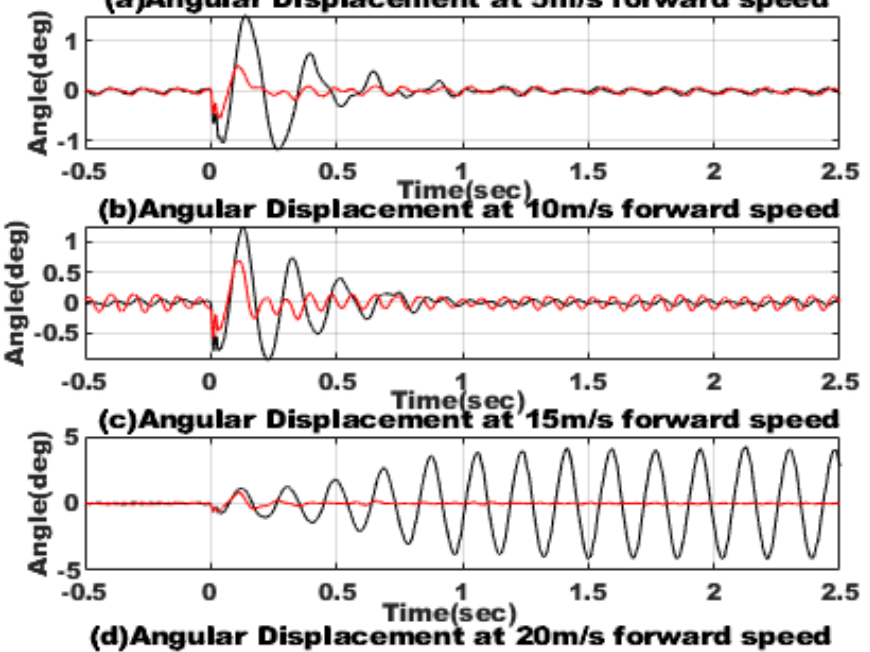

Figure 8. Comparison of time histories between original and no shimmy damper at $140 \mathrm{~N}$ impact force

In Figure 8., Test case\#1 conditions from TABLE II. is used to compare the response of original damper with no shimmy damper. Two methods were used for comparison. First, Shimmy Attenuation Time for peak amplitude to return to within $40 \%$ of steady state amplitude and second, percentage of first peak shimmy amplitude that can be reduced. Though for speeds below $20 \mathrm{~m} / \mathrm{s}$ the system without damper dampen through structural frictional damping, both amplitude and shimmy attenuation time are vastly improved with the original damper. The attenuation time and reduction of peak amplitude comparison between the two test conditions at low impact is outlines in TABLE III.

TABLE III. COMPARISON OF SHIMMY ATTENUATION AT 140N IMPACT FORCE

\begin{tabular}{|c|c|c|c|}
\hline \multirow{2}{*}{$\begin{array}{c}\text { Forward } \\
\text { Speed }[\mathrm{m} / \mathrm{s}]\end{array}$} & \multicolumn{2}{|c|}{$\begin{array}{l}\text { Shimmy Attenuation Time for } \\
\text { peak amplitude to return to } \\
\text { within } 40 \% \text { of steady state } \\
\text { amplitude [ms] }\end{array}$} & \multirow{2}{*}{$\begin{array}{c}\text { Percentage } \\
\text { reduction of } \\
\text { peak } \\
\text { amplitude }\end{array}$} \\
\hline & $\begin{array}{l}\text { Without } \\
\text { Shimmy } \\
\text { Damper }\end{array}$ & $\begin{array}{l}\text { With Shimmy } \\
\text { Damper }\end{array}$ & \\
\hline 5 & 561 & 818 & 80.9 \\
\hline 10 & 1140 & 380 & 67.1 \\
\hline 15 & 733 & 372 & 44.6 \\
\hline 20 & No attenuation & 737 & 25.8 \\
\hline
\end{tabular}

In Figure 9. , Test case\#2 conditions from TABLE II. is used to compare original damper with no shimmy damper response. For all speeds peak shimmy angle for original damper remains almost constant at 2 degrees. Looking at the preimpact amplitudes similar to $140 \mathrm{~N}$ impact force, the noise from the system is higher for the damped case specially for $15 \mathrm{~m} / \mathrm{s}$. 


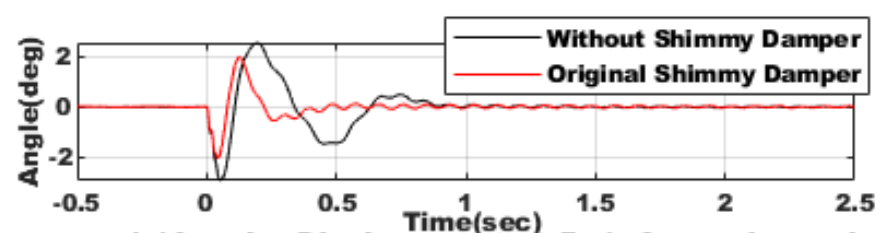

(a)Angular Displacement at $5 \mathrm{~m} / \mathrm{s}$ forward speed

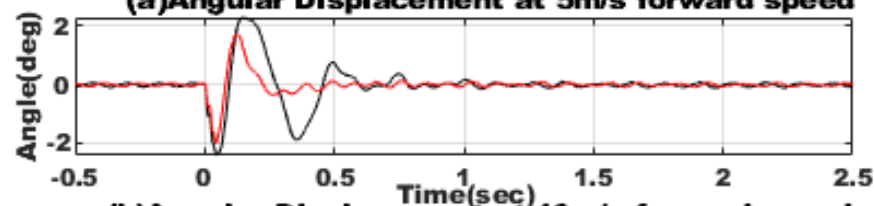

(b)Angular Displacement at $10 \mathrm{~m} / \mathrm{s}$ forward speed

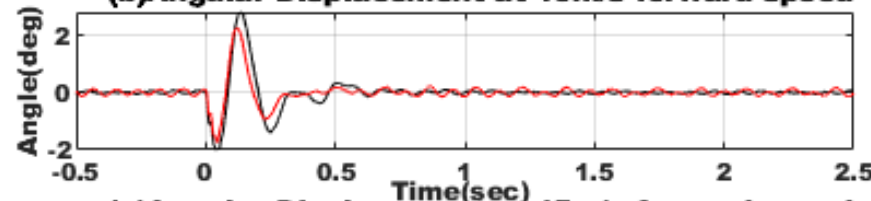

(c)Angular Displacement at $15 \mathrm{~m} / \mathrm{s}$ forward speed

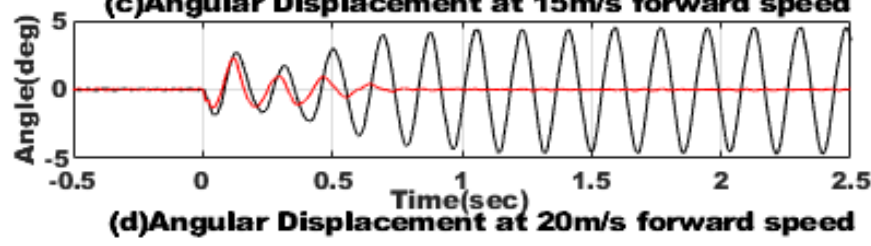

Figure 9. Comparison of time histories between original and no shimmy damper at $400 \mathrm{~N}$ impact force

TABLE IV. COMPARISON OF SHIMMY ATTENUATION AT 400N IMPACT FORCE

\begin{tabular}{|c|c|c|c|}
\hline \multirow{2}{*}{$\begin{array}{c}\text { Forward } \\
\text { Speed[m/s] }\end{array}$} & $\begin{array}{c}\text { Shimmy Attenuation Time for } \\
\text { peak amplitude to return to } \\
\text { within 40\% of steady state } \\
\text { amplitude [ms] }\end{array}$ & \multirow{2}{*}{$\begin{array}{c}\text { Percentage } \\
\text { reduction of } \\
\text { peak } \\
\text { amplitude }\end{array}$} \\
\cline { 2 - 3 } & $\begin{array}{c}\text { Without } \\
\text { Shimmy } \\
\text { Damper }\end{array}$ & $\begin{array}{c}\text { With Shimmy } \\
\text { Damper }\end{array}$ & \\
\hline 5 & 561 & 818 & 80.9 \\
\hline 10 & 1140 & 380 & 67.1 \\
\hline 15 & 733 & 372 & 44.6 \\
\hline 20 & No attenuation & 737 & 25.8 \\
\hline
\end{tabular}

From TABLE IV. we can see similar to low impact case shimmy attenuation time reduces significantly for the original damper at high impact force. The peak amplitude reduction remains constant throughout every speed. This is significant as we see peak amplitude remains almost same for both no damper at 2.5 degrees as well as for original damper at 2 degrees. At 15 $\mathrm{m} / \mathrm{s}$ and $20 \mathrm{~m} / \mathrm{s}$ shimmy attenuation time is $384 \mathrm{~ms}$ and $725 \mathrm{~ms}$ respectively which is almost similar to low impact case. So, it can be said that, in higher speeds attenuation times are remaining constant with change of impact force.

\section{CONCLUSION}

A process of developing a test setup for characterizing landing gear shimmy dampers is presented. During each stage of design, finite element analysis of the structure was performed to avoid coupling of vibration with shimmy frequencies and to keep maximum deformation and linear static stress under limit. The rig can be easily modified to mount any small landing gear. It was tested during experiment for up to $20 \mathrm{~m} / \mathrm{s}$ forward speed and $400 \mathrm{~N}$ of impact force. The rig was also tested for $500 \mathrm{~N}$ of vertical load. An experimental method was developed to measure torsional vibration for different operational condition of the landing gear in order to characterize the performance of shimmy damper. Similar tests had good agreement (amplitude less than $8 \%$, frequency less than $1 \%$ ) with each other. Shimmy amplitude was verified with the use of rotational accelerometer. Testing capability of the rig for unaffected operation during shimmy frequencies of $10-30 \mathrm{~Hz}$ was verified. Some possible sources of error in the results obtained may include not generating the impact moment directly at the landing gear tire, not measuring the torsional vibration responses at the tire rotation which will give higher angular values than measuring at the steering, freeplay at the bolts and washers that affect the system noise within shimmy bandwidth of frequency, drum misalignment, the limited contact between tire surface and drum surface, surface roughness of the drum, original damper limited performance due to its age etc.

\section{REFERENCES}

[1] J. X. Zhou and L. Zhang, "Incremental harmonic balance method for predicting amplitudes of a multi-d.o.f. non-linear wheel shimmy system with combined Coulomb and quadratic damping," J. Sound Vib., 2005.

[2] W. J. Moreland, "Landing-Gear Vibration," WRIGHT AIR DEVELOPMENT CENTER WRIGHT FIELD OH, 1951.

[3] M. Rahmani and K. Behdinan, "On the effectiveness of shimmy dampers in stabilizing nose landing gears," Aerosp. Sci. Technol., 2019.

[4] C. Arreaza, K. Behdinan, and J. W. Zu, "Linear Stability Analysis and Dynamic Response of Shimmy Dampers for Main Landing Gears," $J$. Appl. Mech. Trans. ASME, 2016.

[5] M. Rahmani and K. Behdinan, "Parametric study of a novel nose landing gear shimmy damper concept," J. Sound Vib., 2019.

[6] R. J. Black, "Realistic evaluation of landing gear shimmy stabilization by test and analysis," in SAE Technical Papers, 1976.

[7] K. Ioi, Y. Matsumoto, S. Nishikawa, A. Suda, and M. Tagami, "Study on Shimmy Vibrations of Wheeled Casters," Int. J. Mater. Mech. Manuf., 2015.

[8] D. Takács, "Dynamics of rolling of elastic wheels," Master's Thesis, Budapest University of Technology and Economics, 2005. 